Review Article

\title{
Ocular Manifestations of Alzheimer's and Other Neurodegenerative Diseases: The Prospect of the Eye as a Tool for the Early Diagnosis of Alzheimer's Disease
}

\author{
Pade Colligris $\mathbb{D}^{1,2}$ Maria Jesus Perez de Lara, ${ }^{2,3}$ Basilio Colligris $\mathbb{D D}^{2,3}$ and Jesus Pintor ${ }^{2,3}$ \\ ${ }^{1}$ Universidad Alfonso X, Madrid, Spain \\ ${ }^{2}$ Ocupharm Diagnostics SL, Madrid, Spain \\ ${ }^{3}$ Universidad Complutense de Madrid, Madrid, Spain
}

Correspondence should be addressed to Jesus Pintor; jpintor@ucm.es

Received 2 March 2018; Revised 7 June 2018; Accepted 26 June 2018; Published 30 July 2018

Academic Editor: László Módis

Copyright ( $\odot 2018$ Pade Colligris et al. This is an open access article distributed under the Creative Commons Attribution License, which permits unrestricted use, distribution, and reproduction in any medium, provided the original work is properly cited.

Dementia, including Alzheimer's disease (AD), is a major disorder, leading to several ocular manifestations amongst the elderly population. These visual disorders may be due to retinal nerve degenerative changes, including nerve fibre layer thinning, degeneration of retinal ganglion cells, and changes to vascular parameters. There is no cure for Alzheimer's, but medicines can slow down the development of many of the classic symptoms, such as loss of memory and communication skills, mood swings, and depression. The disease diagnosis is difficult, and it is only possible through PET scans of the brain, detecting evidence of the accumulation of amyloid and tau. PET is expensive and invasive, requiring the injection of radioactive tracers, which bind with these proteins and glow during scanning. Recently, scientists developed promising eye-scan techniques that may detect Alzheimer's disease at its earliest stage, before major symptoms appear, leading to improved management of the disease symptoms. In this review, we are discussing the visual abnormalities of Alzheimer's and other neurodegenerative diseases, focused on ocular functional-visual-structural biomarkers, retinal pathology, and potential novel diagnostic tools.

\section{Introduction}

$\mathrm{AD}$ is a degenerative disorder of the nervous system, eventually affecting over $10 \%$ of individuals aged 65 or over. It is the fifth-leading cause of death among people older than 65 years and a major cause of disability and poor health [1-4]. According to the World Alzheimer Report of 2016, it is estimated that 47 million people suffer from dementia worldwide, and this number could increase to more than 131 million by 2050, as populations age [5]. Life expectancy has increased dramatically over the past century across the globe and consequently has been detected an increase in the observed prevalence of chronic diseases among the elderly people.

While the optical examination sector appears extremely interesting for the development of a novel noninvasive diagnostic tool [6], genome-wide association studies have identified more than $20 \mathrm{AD}$ risk genes [7-10], but the exact mechanism through which these genes are associated with $\mathrm{AD}$ remains unknown [11-13]. More promising are the studies on amyloid precursor protein (APP), presenilin 1 (PSEN1), and presenilin 2 (PSEN2) mutations, identifying them as important factors of autosomal-dominant earlyonset $\mathrm{AD}$ and FAD [14].

As of 2018, there is no modifying therapy for AD [15], and only two families of medications are approved as palliatives for $\mathrm{AD}$ symptoms: the cholinesterase inhibitors and the N-methyl-D-aspartate receptor (NMDAR) antagonists, while various new drugs are under clinical trials evaluations, among them the promising new family of secretase inhibitors [16-18].

Even though many preclinical and clinical trials on $\mathrm{AD}$ drugs are underway, it is becoming obvious that the concept of the simplistic therapy of one compound against one target is failing, due to the complex pathophysiology of the disease, and future treatment will be based on drug combinations to 
intensify the results [19]. In any case, the onset of Alzheimer's disease cannot yet be stopped or reversed but might be manageable.

Diagnosis of the disease is difficult and frequently is subjective. There is no single diagnostic test and specialists are using various methods, including physical examination and brain scans, such as computed tomography (CT), magnetic resonance imaging (MRI), or positron emission tomography (PET), to rule out other probable causes for the symptoms [20]. For the moment, early diagnosis is based on the early recognition of the various signs and symptoms, as the most common sign of the disease is memory loss, especially forgetting recently learned information.

Generally, a timely and accurate diagnosis is considered to be important, as treatment of Alzheimer's and other dementia-causing diseases is typically most effective when started early in the disease process [21, 22]. Additionally, accurate diagnosis could transform the design and execution of clinical trials to test new $\mathrm{AD}$ treatments [23-27].

Current diagnosis methods mainly rely either on subjective tests or invasive methods with a limited accuracy. Definite AD diagnosis is possible only through postmortem observation of the aberrant accumulation of $\beta$-amyloid peptides $(\mathrm{A} \beta)$ extracellular aggregates, $\beta$-amyloid plaques, and protein tau intracellular twisted strands (neurofibrillary tangles, NFTs) [26-31]. The inaccuracy of the existing diagnostic methods, limits the general applicability for vast population screening and underlines the need for the identification of easily accessible tools for the identification of high-risk subjects. To better serve the population at risk of developing $\mathrm{AD}$, new methods of definitive, noninvasive and lower cost diagnosis are needed.

$\mathrm{AD}$ could be categorized in familial Alzheimer's disease (FAD, also known as early-onset Alzheimer's disease) and sporadic type (also known as late onset Alzheimer's disease; LOAD) [32]. The eye offers a natural window to the brain as the retina, the light-sensitive layer lining the interior of the eye is considered part of the central nervous system (CNS) and the only optically accessible nervous tissue [33]. Neurodegenerative changes in the brain produced by $\mathrm{AD}$ are accompanied by structural and possible functional changes in the neuroretina and the ocular vasculature.

Numerous recent studies reported the presence of $\beta$-amyloid plaques in the retina of patients, opening the possibility of detecting $\mathrm{AD}$ though simple noninvasive eye scans [34-38]. In a parallel way, other studies revealed degenerative changes and retinal neuron damage in the retina/eye of $\mathrm{AD}$ animal models [39-43]. Consequently, various laboratories are trying to explore this approach, developing optical retinal imaging platforms capable to detect $\beta$-amyloid plaques in the retina of $\mathrm{AD}$ subjects $[38,44-48]$. These novel imaging platforms are expected to early detect the presence of $\mathrm{AD}$ hallmarks and assist in monitoring the efficacy of probable future therapeutic agents which target relevant molecular pathways.

Nevertheless, Alzheimer's disease shares common features, mode-of-action, and targets with other neurodegenerative diseases such as, Parkinson's disease, Huntington's disease, amyotrophic lateral sclerosis, frontotemporal dementia, and even glaucoma and macular degeneration [49-52]. Therefore, in the following text, we will analyse the relation between $\mathrm{AD}$ and some of these neurodegenerative disorders, focusing on their ocular manifestations on the accessible retina, and the possibility of using these hallmark signs as structural-functional biomarkers for risk assessment-monitoring of disease progression, and evaluation for the drug therapeutic efficacy. In any case, the establishment of a link between neurodegenerative diseases and ocular manifestations is an interesting emerging field of study.

\section{Detection and Pathophysiological Processes Involved in Alzheimer's Diseases and Other Neurodegenerative Diseases}

Several studies have focused upon the relationship between neurodegenerative diseases and their possible ocular manifestation. There is compelling evidence to suggest that specific ocular biomarkers related to neurodegenerative disorders play a pivotal role in the development of retinal impairment or loss of visual function $[53,54]$.

The abnormal protein aggregation characterizes numerous neurodegenerative diseases, where insoluble proteins are accumulated in the brain such as $\mathrm{AD}$, the Prion Encephalopathies, Parkinson's disease, Huntington disease, and other polyglutamine disorders [55]. Protein misfolding diseases are not exclusive to the CNS, including disorders implicating amyloidogenic proteins like type 2 diabetes, inherited cataracts, vascular inflammation, atherosclerosis, and haemodialysis-related disorders, among many others [56]. Goldstein et al. reported the detection of nanoaggregates of $\beta$-amyloid in the human $\mathrm{AD}$ lens [57], a non-CNS structure considering another relevant ocular hallmark in this pathology. Deposits of $\beta$-amyloid are a distinct characteristic found in neurodegenerative diseases AD [58-60], Parkinson's disease [60-65], as well as being detected in age-related macular degeneration [66], and glaucoma [67-70].

In fact, there are numerous recent studies connecting glaucoma and $\mathrm{AD}$, and some, bearing in mind the multiple common features to both diseases, including risk factors and pathophysiological mechanisms, are suggesting that Alzheimer's Disease and glaucoma should be considered age-related neurodegenerative diseases, coexisting in the elderly population [71-74]. Adding to the connection link theories between glaucoma and $\mathrm{AD}$ is the recent unifying hypothesis of the "glymphatic system." This hypothesis is incorporating various aspects of the vascular, biomechanical, and biochemical theories, based on a few studies suggesting the existence of a paravascular transport system in the eye and optic nerve. However, for the moment, there are not sufficient available research data to totally support this idea [75-78].

On the other hand, recent studies are suggesting that $\mathrm{AD}$ and age-related macular degeneration (AMD) share common, pathological signalling defects and disease mechanisms at the molecular genetic level $[79,80]$. There is 
growing evidence that $\beta$-amyloid, the main component of senile plaques, the hallmark of $\mathrm{AD}$, is also a vital component of drusen, the hallmark of AMD [81-83]. While AMD is a retinal disease, $\mathrm{AD}$ is damaging the brain cells as well as the retina. These two age-related diseases are primarily affecting distinct parts of the central nervous system but are generally similar, concerning the abnormal extracellular deposits, metabolic and oxidative stress, neuroinflammation, and microvascular abnormalities [81, 84].

$\mathrm{AD}$ is characterized by visual disturbances at early stages which are correlated to neuronal damage in the inner retina, loss of RGCs, and optic nerve degeneration at postmortem histology, as suggested by several authors $[37,38,85-91]$ and is also correlated to Parkinson's disease, as suggested by Bayer et al. [92]. Further studies reported that these inner retinal alterations were correlated with an abnormal pattern electroretinography ( $\mathrm{pERG)}$ response [93]. From the earliest stages of the disease, amyloid plaque is deposited in retina tissue (including the RGC, retinal nerve fibre layer-RNFL, and inner plexiform layer) which can produce a fluorescence effect by using curcumin as a contrast [94].

An important characteristic of many systemic processes related to $\mathrm{AD}$ is the contribution of the energy metabolism, albeit the role of altered metabolic processes implicated in Alzheimer's disease pathogenesis is still unclear [95]. Recent studies discovered that in several CNS disorders, there is evidence of circulating metabolites signatures, suggesting that retinal oxygen metabolism in $\mathrm{AD}$ is slightly different from the normal, even though the results are not conclusive (ClinicalTrials.gov Identifier: NCT02253732; ClinicalTrials. gov Identifier: NCT00001972) [96, 97]. Following this discovery, the University of Iceland, Reykjavík, Iceland, is developing a biomarker for $\mathrm{AD}$ albeit further studies are necessary, using larger groups, to verify the results and further metabolomic studies and are imperative to demonstrate the correlation between systemic abnormalities and the brain impairment in $\mathrm{AD}$ [60].

The Spanish Hospital Universitari Vall d'Hebron Research Institute is investigating the association between type 2 diabetes (T2D) and Alzheimer's disease (AD) $[98,99]$ and in September 2014, started a clinical trial (ClinicalTrials.gov Identifier: NCT02360527) to explore whether diabetic patients are at risk of developing $\mathrm{AD}$ based on the assessment of retinal neurodegeneration and if these retina irregularities are related to the severity of $\mathrm{AD}$. The results suggest that retinal sensitivity, assessed by microperimetry, is related to brain neurodegeneration and could be a useful biomarker for the detection of the disease [100].

In the University Hospital of Bordeaux, scientists are studying how the reduced thickness of RNFL relates to $A D$ and other degenerative diseases and if RNFL thickness is associated with the development of cognitive impairment. They suggest that this parameter could be used as a biomarker for cerebral axonal degeneration, as RNFL deficits could be an early sign of $\mathrm{AD}$, even before damages occur in the hippocampal region (ClinicalTrials.gov Identifier: NCT01621841- ClinicalTrials.gov Identifier: NCT01555827) [101-104]. The results confirm that the RNFL thickness is associated with changes in patients' memory and could be used as an indicator for the future development of $\mathrm{AD}$ [104].

In another instance, in the Department of Neurosurgery and Maxine Dunitz Neurosurgical Research Institute, Cedars-Sinai Medical Centre, Los Angeles, trials have begun to administrate intravenous therapy of curcumin, a fluorophore with high affinity to $\mathrm{A} \beta$, to an $\mathrm{AD}-\mathrm{Tg}$ mice $(n=24)$ mouse model and performed fluorescent retinal examination in vivo [34]. After systemic administration of curcumin using this method, noninvasive optical imaging of retinal $\beta$-amyloid plaques in vivo with high resolution and specificity was allowed [105]. Curcumin is used as an early diagnostic probe due to its inherited fluorescence and high binding affinity to amyloid- $\beta$, but it could also be the basis of new drugs for the prevention and treatment of $\mathrm{AD}$ [106].

In 2011, Koronyo-Hamaoui and colleagues described the presence of $\beta$-amyloid in human retinal whole mount of $\mathrm{AD}$. Posterior studies showed the predominant superior hemiretina damage involving mainly the inner retinal layers and histological analysis provided evidence of increased $A \beta P P$ in $\mathrm{AD}$ retinas [5, 34, 49, 107]. In addition, specific retinal ganglion cells (RGC) and melanopsin retinal ganglion cells (mRGC) are affected by amyloid pathology in AD in and around cells [37].

Numerous studies of transgenic rodent models of $\mathrm{AD}$ have identified retinal $A \beta$ depositions in the inner retina (inner plexiform layer, RGC layer, and nerve fibre layers) and the outer nuclear layer. These findings correlate with the burden of amyloid plaques in the brain [34, 38, 107-109]. Furthermore, the pathological mechanisms that involve $\beta$-amyloid in neuronal death are similar between RGC loss and neuronal degeneration in hippocampus in different models of AD [66, 85-90, 110]. RGC apoptosis was accompanied by and localized with $\mathrm{A} \beta$ deposits in retinas from rodent models, and signalling pathways are similar in retinal and hippocampal neurons death $[107,111]$. Based on the observation on the retina of $\beta$-amyloid plaques, various companies and research centres started the development of specific biomarkers for the $\mathrm{AD}$ early diagnosis. In December 4, 2017 the Canadian company Optina Diagnostics Inc. started the ClinicalTrials.gov Identifier: NCT03420807 for the evaluation of a device called metabolic hyperspectral retinal camera (MHRC) for the detection of $\beta$-amyloid plaques. A hyperspectral mydriatic camera is used, producing multiple images of the retina, collecting and processing the light intensity for a large number (225) of contiguous spectral bands at high speeds allowing the noninvasive localization of structures and biomolecules in the retina evaluating their specific spectral signatures [112-114]. This method is based on the $\beta$-amyloid plaques hypothesis of $\mathrm{AD}$ pathophysiology, even though it generally remains unproven by clinical interventions [115].

Other studies support the hyperspectral imaging microscopy (HSI) method, to examine A $\beta$ presence without the need for exogenous fluorophore. More and colleagues demonstrated the spectral signature of aggregated $A \beta$ in $A D$ mice model retinas and in vivo detection $[116,117]$.

While the optical examination sector appears extremely interesting for the development of a novel noninvasive 
diagnostic tool, for the moment, research has barely surpassed the animal model level, and there is limited proof yet that it is possible to detect $\beta$-amyloid plaques in the retina by visual means.

In addition to growing reports of retinal $\mathrm{A} \beta$ accumulation, other established hallmark of $\mathrm{AD}$ is pTau protein aggregates. Alterations in tau protein and gene expression were found in a triple transgenic mouse model revealing neuronal dysfunction that precedes cell death in the AD retina. In addition, these results were correlated to the presence of tau accumulation in the RGC soma and dendrites [38, 41, 118, 119]. Hyperphosphorylated tau was detected in postmortem human retinas and in $\mathrm{AD}$ animal models, which led us to the hypothesis that this could be observed at a presymptomatic stage of the disease as tau aggregation was not detected [118, 120, 121].

$\mathrm{AD}$ is a progressive brain disorder, with strong genetic determinants and aggregated protein, responsible for dementia. For many decades, the main environmental factors that influence the risk of $\mathrm{AD}$ development have been thoroughly studied. The primary risk factors involve hypertension, diabetes, hyperlipidaemia, metabolic syndrome, unhealthy diet, smoking, and physical inactivity among others $[1,122,123]$. It is considered that all these factors may contribute to the dilapidated physiopathological mechanisms in $\mathrm{AD}$ development.

Detection of specific biomarkers or advanced AD diagnosis approaches in the preclinical stage would be a potential breakthrough in the management of AD. Recent studies suggest that the retinal alterations occur early, thereby suggesting the necessity of earlier diagnosis and subsequent treatment of AD. Retinal imaging could, therefore, serve as an alternative approach to assessing brain degeneration in $\mathrm{AD}$. Over the last 15 years, a noninvasive optical imaging technique of the retina and OHN has been used as a valuable tool to assess the optic nerve pathology in $\mathrm{AD}$. In vivo detection of amyloid deposits in $\mathrm{AD}$ retinas were reported using OCT, and findings included perimacular and perivascular spots in the outer plexiform layer (OPL), ganglion cell layer (GCL), and the nerve fibre layer (NFL) thinning in AD [124-127].

In the Commonwealth Scientific and Industrial Research Organisation (CSIRO), Perth, WA, Australia, scientists began a study of $\mathrm{AD}$ patients, to discover whether the vascular analysis of retinal photographs could identify any retinal vascular parameters (RVPs) and when these retinal changes occur. The study demonstrated that retinal vascular biomarker is a potential method for the early detection of AD [128]. Likewise, researchers in Duke University of London developed a diagnostic method based on retinal imaging. In July 2017, a clinical trial with reference ClinicalTrials.gov Identifier: NCT03233646 was undertaken to evaluate a noninvasive OCTA-based retinal microvascular biomarker, as an effective screening tool in cognitive aging. The investigators hypothesize that microvascular network alterations in the retina mirror and possibly precede changes in the cerebral microcirculation seen in AD. Using advanced image analysis, the investigators aim to evaluate markers of reduced capillary blood flow and nonperfusion in the superficial and deep retinal vascular plexuses and choriocapillaris imaging using OCTA that would complement already established retinal-structural markers and increase their sensitivity and specificity in the early detection of AD. Various studies found that patients with $\mathrm{AD}$ have less density of retinal microvascular networks than the normal, considering retinal vessel reaction to flicker stimulation as a promising noninvasive, widely available, and easy-toadminister future biomarker for the diagnosis and monitoring of $\mathrm{AD}[129,130]$. In another study, the OCTA technique was tested on patients with $\mathrm{AD}$, demonstrating its efficacy as a biomarker in the early diagnosis of the disease [131]. Additionally, the Medical University of Vienna is investigating whether more functional changes can be detected in the retina of $\mathrm{AD}$ patients, in conjunction with the already identified aberrations. For this purpose, in September 2016, they began a clinical trial (ClinicalTrials.gov Identifier: NCT02663531) evaluating the relationship between neural activity and blood flow, in induced flicker light hyperaemia in the retina, as a possible biomarker for AD. Furthermore, they assessed structural parameters such as retinal nerve fibre layer thickness and function parameters such as ocular blood flow and retinal oxygenation $[132,133]$. According to the results, neuritic plaques were detected in representative cortical regions, suggesting OCTA as a useful tool for three-dimensional imaging of retinal $\mathrm{A} \beta$ accumulation $[134,135]$.

In general, advances in the image processing and software have improved the interpreting of anterior segment OCT images. In any case, the technique must advance towards the refinement of assessing vascular networks for the anterior segment and improvement of the histology detail, to become more accurate and to facilitate its use.

Studying the retinal visual changes of patients with neurodegeneration is an emerging field that requires more investigation. Intraocular and systemic therapeutic biomarkers/agents and visualizing techniques may be developed, serving the dual purposes of establishing novel pharmacological targets and new technological sources.

The mentioned areas of research have come a long way with many and important results, allowing us to have a better understanding of the disease [47]. More efforts are still needed, however, to fully understand the aetiology of the disease, to establish reliable individual predictive models, and place us closer to the development of a definitive diagnostic method and a possible personalized treatment.

\section{Ophthalmological and Ocular Clinical Symptoms}

The ocular alterations in AD involve different structures in the anterior and posterior pole (Table 1). In the anterior pole, tear fluid is considered to be a potential biomarker source. Kallo et al. discovered 100\% increase of flow rate and 100\% increase in protein levels in $\mathrm{AD}$ patients, with respect to the age-matched controls. The combination of four tear proteins lipocalin-1, dermicidin, lysozyme $\mathrm{C}$ and lactritin, had $81 \%$ sensitivity and $77 \%$ specificity for AD [136]. Furthermore, abnormal tear functions and reduced corneal sensibility were described in previous studies of neurodegenerative 
TABLe 1: Visual system pathological and functional alterations in Alzheimer's disease.

\begin{tabular}{|c|c|}
\hline Ocular structures and clinical facts & Pathological changes \\
\hline Retina & $\begin{array}{c}\text { Deposition of proteins tau, } \mathrm{A} \beta \text {, and pTAu }[35,38,39,118] \text {; accumulation of phosphorylated } \\
\text { tau protein }[138,139] \\
\text { Impairment of amyloid } \beta \text { precursor protein (APP) metabolism }[140,141,142] \\
\text { Reduction in retinal ganglion cells (RGCs) }[85-87,143] \\
\text { Reduction of retinal thickness }[85,93,144] \\
\text { Reduction to the retinal nerve fibre layer (RNFL) thickness }[89,145] \\
\text { Retrograde degeneration from loss of cortical neurons }[146,147] \\
\text { Inflammation }[148,149,150]\end{array}$ \\
\hline Retinal and choroidal vasculature & $\begin{array}{c}\text { Retinal and choroidal vascular } \beta \text {-amyloid deposits in transgenic mouse model of AD lead to } \\
\text { retinal degeneration [107] } \\
\text { Reduction of vascularization [151] }\end{array}$ \\
\hline Retinal vascular blood flow & Blood flow abnormalities may cause neurodegeneration [152] \\
\hline Optic nerve & $\begin{array}{c}\text { Axonal degeneration in the axonal segments }[85,140] \\
\text { Loss of optic nerve thickness }[153,154] \\
\text { Papillary paleness due to axonal loss and perfusion alterations [155] }\end{array}$ \\
\hline Lens & $\begin{array}{c}\text { Correlation between } \mathrm{AD} \text { and supranuclear cataract }[156,157] \\
\text { Presence of abnormal protein deposits }[124,157]\end{array}$ \\
\hline $\begin{array}{l}\text { Tears } \\
\text { Cornea }\end{array}$ & $\begin{array}{c}\text { Changes in the chemical barrier composition of tears [136] } \\
\text { Reduced corneal sensitivity [137] }\end{array}$ \\
\hline $\begin{array}{l}\text { Pupil } \\
\text { Choroid }\end{array}$ & $\begin{array}{c}\text { Pupillary responses possible biomarker }[158,159] \\
\text { Attenuation of choroidal thickness }[160,161]\end{array}$ \\
\hline Aqueous humour & $\begin{array}{c}\text { Detection of Alzheimer connected, } \beta \text {-amyloid peptides, and chemokines in the aqueous } \\
\text { humour }[162,163]\end{array}$ \\
\hline $\begin{array}{l}\text { Visual field } \\
\text { Visual acuity }\end{array}$ & $\begin{array}{c}\text { Dysfunction in different tasks of basic vision and visual cognition [164] } \\
\text { Decreased visual acuity [165] }\end{array}$ \\
\hline $\begin{array}{l}\text { Sensory perception } \\
\text { Visual processing }\end{array}$ & $\begin{array}{c}\text { Clinically important symptoms of visuospatial disorientation }[166,167] \\
\text { Deficits of visual motion perception }[168]\end{array}$ \\
\hline $\begin{array}{l}\text { Contrast sensitivity } \\
\text { Colour vision }\end{array}$ & $\begin{array}{l}\text { Contrast sensitivity disturbances and motion perception }[169,170] \\
\text { Incomplete achromatopsia }[171]\end{array}$ \\
\hline Stereopsis & Reduced stereoscopic depth perception $[172,173]$ \\
\hline Circadian rhythm & $\begin{array}{l}\text { Alterations in the circadian rhythm and } \beta \text {-amyloid deposits inside and surrounding } \\
\text { degenerating mRGCs [174-176] }\end{array}$ \\
\hline
\end{tabular}

diseases [137]. In 2017, the French company Amoneta Diagnostics SAS started a clinical trial (ClinicalTrials.gov Identifier: NCT03030586) to validate the performance of a noninvasive peripheral blood diagnostic kit for $\mathrm{AD}$, collecting samples from peripheral body fluids, tears being among them.

Pupillary responses are associated with brain impairment in different studies where light reflex amplitude is reduced in AD [177]. Granholm et al. suggest that taskevoked pupillary responses may be a psychophysiological biomarker of early risk for AD [158]. The Massachusetts General Hospital started a clinical trial (ClinicalTrials.gov Identifier: NCT03330353) in 2017 to investigate rod, cone, and melanopsin-driven pupillary light response in individuals, as a possible AD and other neurodegenerative diseases diagnostic method. Furthermore, the Centre Hospitalier Universitaire de Besancon France recently began a clinical trial (ClinicalTrials.gov Identifier: NCT01434940) to validate eye movement recording as an early differential diagnostic tool for AD. Tracking eye movements is becoming an interesting diagnostic technique and could be beneficial in recognizing individuals who will progress to $\mathrm{AD}$, but for the moment, there remain many critical points which require additional investigation.
As previously commented, $\beta$-amyloid was detected in the human lens of $\mathrm{AD}$ patients, and in a Framingham Offspring Eye Study cohort, a correlation between cortical cataract and AD degeneration was observed $[124,156,178,179]$. These findings establish the $\beta$-amyloid protein as a key pathogenic biomarker between lens and AD. In 2017, the American company Cognoptix, Inc. started a clinical trial to $\operatorname{detect} \beta$-amyloid in the lens of the eye in patients with mild cognitive impairment (MCI), and mild AD after the instillation of Aftobetin Hydrochloride. Aftobetin, also known as ANCA11 and NCE-11, is an amyloid-binding compound applied topically in the form of an ophthalmic ointment and may be useful as an aid in the diagnosis of AD (ClinicalTrials.gov Identifier: NCT02928211).

Finally, in another ocular fluid, the aqueous humour; higher levels of proteins involved in AD pathology such as $\beta$-amyloid peptides; and a series of chemokines, including eotaxin, eotaxin 3, and interleukin [IL]-8 (160) were detected in cataract surgery patients. Additionally, Inoue et al. suggest that open-angle glaucoma patients presented elevated levels of various biomarkers of $\mathrm{AD}$ in the aqueous humour, including apolipoprotein (Apo) AI, ApoCIII, ApoE, transthyretin (TTR), complement factor $\mathrm{H}$, complement $\mathrm{C} 3$, and $\alpha 2$-macroglobulin $(\alpha 2 \mathrm{M})$ [162]. 
In the posterior pole, retinal thickness is correlated to cortical atrophy and choroid and NFL is thinning in AD patients $[85,93,144,145,153,155,160]$. Several reports in AD patients, showed RGC loss [85, 86, 143]. Additionally, studies in patients and on $\mathrm{AD}$ animal models displayed $\mathrm{A} \beta$ and tau proteins accumulation in inner retinal layers [138, 143, 180]. Furthermore, Rusu et al. detected APP metabolism impairment in transgenic drosophila [140] and Paris et al. detected a reduction of angiogenesis processes in transgenic mice [151]. In addition, studies on patients and animal models reveal that activated microglia and proinflammatory molecules are contributing to the development of the pathology, and they are degenerating neurons, decreasing retinal activity $[111,148,149,181]$.

All these morphological and/or biochemical changes are leading to decreased visual acuity, deficits in visual perception, anomalies of colour vision, visual cognition impairment, and visuospatial disorientation. In summary, all these findings are creating the certainty that visual abnormalities of the visual axis, from RGC to visual cortex, are common ocular characteristic features of $\mathrm{AD}[164-166,168]$.

\section{Conclusions}

$\mathrm{AD}$ diagnosis is based on the interpretation of the signs and symptoms of the disease in cerebrospinal fluid (CSF) tests and neuroimaging of the brain. Recent major advances in brain imaging are providing opportunities for a more accurate diagnosis, but unfortunately, this technique has limited availability, and its costs are high, making population-wide screening challenging. Consequently, there is a global need for novel early diagnostic methods, more specific, more economic, and with the added ability to distinguish $\mathrm{AD}$ among the diverse types of neurodegenerative disorders, bearing in mind that $\mathrm{AD}$ diagnosis must identify the disease before the cognitive deficits have reached the threshold of dementia.

The eye shares many neural and vascular similarities with the brain, directing many researchers towards the discovery and development of novel ocular biomarkers, which could have a profound influence on early diagnosis and the discovery of new treatments for the disease.

Numerous recent studies reported the presence of $\beta$-amyloid plaques, the hallmark of the disease, in the retina of AD mice models and humans, opening the possibility of detecting $\mathrm{AD}$ through a simple noninvasive eye scan. Various laboratories are exploring this approach with the development of optical retinal imaging platforms to detect $\beta$-amyloid plaques in the retina of AD subjects. These novel imaging platforms are expected to help aid the early detection of $\mathrm{AD}$ and assist in monitoring the efficacy of probable future therapeutic agents which target relevant molecular pathways.

Another imminent change concerning the diagnosis of the neurodegenerative diseases through the eye would be the greater role of the primary eye care practitioners in a sector that previously had little implication.

While a considerable number of clinical trials are currently underway to evaluate novel diagnostic methods, through the eye, and the results are promising, for the moment, the biomarkers for the diagnosis of Alzheimer's disease $(\mathrm{AD})$ are not yet validated for use in clinical settings, and their widespread implementation remains a challenge. Among the reasons for this, we could underline the lack of experience of the researchers to interpret the huge data obtained from these eye images, ethnic variation causing further complications, the overlap with other diseases, and the lack of specificity of these biomarkers. In general, there is a need for a greater number of validation studies involving wider cohorts of various ethnicities and origins. Another question arising in the use of eye biomarkers is that perhaps they are too late as by the time $\beta$-amiloide plaques are discovered in the retina, the disease has already progressed.

Finally, the cascade of events resulting in retinal cell death in ocular neurodegenerative pathologies is leading scientists to a new common descriptive term of diseases of the retina. Even though the aetiology of AMD, glaucoma, and $\mathrm{AD}$ is still uncertain, studying the common features between them may provide further knowledge about their pathogenesis and could lead to accelerated development of therapies for both diseases. Additionally, studying ADrelated retinal degeneration is a promising way forward in the investigation of $\mathrm{AD}$ pathologies and therapies, which could eventually benefit the brain and cellular mechanisms in other retinal degenerations.

\section{Conflicts of Interest}

There are no existing conflicts for this publication.

\section{Authors' Contributions}

Pade Colligris and Maria Jesus Perez de Lara contributed equally to the manuscript.

\section{Acknowledgments}

This review was supported by the research grants of SAF2016-77084-R and RETICS RD16/0008/0001.

\section{References}

[1] Alzheimer's Association, “2013 Alzheimer's disease facts and figures," Alzheimer's and Dementia, vol. 9, no. 2, pp. 208245, 2013.

[2] H. W. Querfurth and F. M. LaFerla, "Alzheimer's disease," New England Journal of Medicine, vol. 362, no. 4, pp. 329344, 2010.

[3] M. Kivipelto, E. L. Helkala, M. P. Laakso et al., "Midlife vascular risk factors and Alzheimer's disease in later life: longitudinal, population based study," BMJ, vol. 322, no. 7300 , pp. 1447-1451, 2001.

[4] J. A. Luchsinger and D. R. Gustafson, "Adiposity, type 2 diabetes, and Alzheimer's disease," Journal of Alzheimers Disease, vol. 16, no. 4, pp. 693-704, 2009.

[5] S. Ahtiluoto, T. Polvikoski, M. Peltonen et al., "Diabetes, Alzheimer's disease, and vascular dementia a populationbased neuropathologic study," Neurology, vol. 75, no. 13, pp. 1195-1202, 2010. 
[6] I. Moonga, F. Niccolini, H. Wilson, G. Pagano, and M. Politis, "Neuroimaging AsD. Hypertension is associated with worse cognitive function and hippocampal hypometabolism in Alzheimer's disease," European Journal of Neurology, vol. 24, no. 9, pp. 1173-1182, 2017.

[7] F. F. Oliveira, G. V. Almeida, S. S. Almeida, E. S. Chen, M. A. C. Smith, and P. H. F. Bertolucci, "Pharmacogenetics of angiotensin receptor blockers in patients with dementia due to Alzheimer's disease," European Journal of Neurology, vol. 24, p. 613, 2017.

[8] J. J. Pruzin, J. A. Schneider, A. W. Capuano et al., "Diabetes, hemoglobin A1C, and regional Alzheimer disease and infarct pathology," Alzheimer Disease and Associated Disorders, vol. 31, no. 1, pp. 41-47, 2017.

[9] E. Rojas-Gutierrez, G. Munoz-Arenas, S. Trevino et al., "Alzheimer's disease and metabolic syndrome: a link from oxidative stress and inflammation to neurodegeneration," Synapse, vol. 71, no. 10, article e21990, 2017.

[10] R. E. Tanzi, "The genetics of Alzheimer's disease," Cold Spring Harbor Perspectives in Medicine, vol. 2, no. 10, article a006296, 2012.

[11] C. Iadecola, "The pathobiology of vascular dementia," Neuron, vol. 80, no. 4, pp. 844-866, 2013.

[12] A. Kapasi and J. A. Schneider, "Vascular contributions to cognitive impairment, clinical Alzheimer's disease, and dementia in older persons," Biochimica et Biophysica Acta, vol. 1862, no. 5, pp. 878-886, 2016.

[13] L. G. Apostolova, S. L. Risacher, T. Duran et al., "Associations of the top 20 Alzheimer disease risk variants with brain amyloidosis," JAMA Neurology, vol. 75, no. 3, p. 328, 2018.

[14] H. M. Lanoiselee, G. Nicolas, D. Wallon et al., "APP, PSEN1, and PSEN2 mutations in early-onset Alzheimer's disease: a genetic screening study of familial and sporadic cases," PLoS Medicine, vol. 14, no. 3, article e1002270, 2017.

[15] J. L. Cummings, T. Morstorf, and K. Zhong, "Alzheimer's disease drug-development pipeline: few candidates, frequent failures," Alzheimer's Research and Therapy, vol. 6, no. 4, p. 37, 2014

[16] E. J. Mufson, S. E. Counts, S. E. Perez, and S. D. Ginsberg, "Cholinergic system during the progression of Alzheimer's disease: therapeutic implications," Expert Review of Neurotherapeutics, vol. 8, no. 11, pp. 1703-1718, 2008.

[17] A. Kumar, C. M. Nisha, C. Silakari et al., "Current and novel therapeutic molecules and targets in Alzheimer's disease," Journal of the Formosan Medical Association, vol. 115, no. 1, pp. 3-10, 2016.

[18] D. Kumar, A. Ganeshpurkar, D. Kumar, G. Modi, S. K. Gupta, and S. K. Singh, "Secretase inhibitors for the treatment of Alzheimer's disease: long road ahead," European Journal of Medicinal Chemistry, vol. 148, pp. 436-452, 2018.

[19] A. K. Sahoo, J. Dandapat, U. C. Dash, and S. Kanhar, "Features and outcomes of drugs for combination therapy as multi-targets strategy to combat Alzheimer's disease," Journal of Ethnopharmacology, vol. 215, pp. 42-73, 2018.

[20] M. W. Weiner, D. P. Veitch, P. S. Aisen et al., "The Alzheimer's disease neuroimaging initiative: a review of papers published since its inception," Alzheimer's and Dementia: The Journal of the Alzheimer's Association, vol. 8, no. 1, pp. S1-S68, 2012.

[21] M. E. de Vugt and F. R. Verhey, "The impact of early dementia diagnosis and intervention on informal caregivers," Progress in Neurobiology, vol. 110, pp. 54-62, 2013.

[22] L. Robinson, E. Tang, and J. P. Taylor, "Dementia: timely diagnosis and early intervention," BMJ, vol. 350, article h3029, 2015.
[23] G. M. McKhann, D. S. Knopman, H. Chertkow et al., “The diagnosis of dementia due to Alzheimer's disease: recommendations from the National Institute on AgingAlzheimer's Association workgroups on diagnostic guidelines for Alzheimer's disease," Alzheimer's and Dementia: The Journal of the Alzheimer's Association, vol. 7, no. 3, pp. 263-269, 2011.

[24] W. M. van der Flier, Y. A. Pijnenburg, N. C. Fox, and P. Scheltens, "Early-onset versus late-onset Alzheimer's disease: the case of the missing APOE varepsilon4 allele," Lancet Neurology, vol. 10, no. 3, pp. 280-288, 2011.

[25] P. Scheltens, K. Blennow, M. M. Breteler et al., “Alzheimer's disease," The Lancet, vol. 388, no. 10043, pp. 505-517, 2016.

[26] R. D. Terry, E. Masliah, and L. A. Hansen, "Structural basis of the cognitive alterations in Alzheimer disease," in Alzheimer Disease, R. D. Terry, R. Katzman, and K. L. Bick, Eds., Raven Press, New York, NY, USA, 1994.

[27] E. M. Mandelkow and E. Mandelkow, "Tau in Alzheimer's disease," Trends in Cell Biology, vol. 8, no. 11, pp. 425-427, 1998.

[28] J. Q. Trojanowski and V. M. Lee, “"Fatal attractions” of proteins: a comprehensive hypothetical mechanism underlying Alzheimer's disease and other neurodegenerative disorders," Annals of the New York Academy of Sciences, vol. 924, no. 1, pp. 62-67, 2000.

[29] K. Iqbal and I. Grundke-Iqbal, "Neurofibrillary pathology leads to synaptic loss and not the other way around in Alzheimer disease," Journal of Alzheimer's Disease, vol. 4, no. 3, pp. 235-238, 2002.

[30] B. Liu, S. Rasool, Z. Yang et al., "Amyloid-peptide vaccinations reduce $\{$ beta\}-amyloid plaques but exacerbate vascular deposition and inflammation in the retina of Alzheimer's transgenic mice," American Journal of Pathology, vol. 175, no. 5, pp. 2099-2110, 2009.

[31] L. Crews and E. Masliah, "Molecular mechanisms of neurodegeneration in Alzheimer's disease," Human Molecular Genetics, vol. 19, no. R1, pp. R12-R20, 2010.

[32] M. Saadat, "Distributions of susceptibility loci to late onset Alzheimer's disease on human chromosomes," EXCLI Journal, vol. 15, pp. 403-405, 2016.

[33] B. A. Wandell, Foundations of Vision, Stanford University, Stanford, CA, USA, 2013.

[34] M. Koronyo-Hamaoui, Y. Koronyo, A. V. Ljubimov et al., "Identification of amyloid plaques in retinas from Alzheimer's patients and noninvasive in vivo optical imaging of retinal plaques in a mouse model," Neuroimage, vol. 54, no. 1, pp. S204-S217, 2011.

[35] Y. Koronyo, B. C. Salumbides, K. L. Black, and M. KoronyoHamaoui, "Alzheimer's disease in the retina: imaging retinal abeta plaques for early diagnosis and therapy assessment," Neuro-Degenerative Diseases, vol. 10, no. 1-4, pp. 285-293, 2012.

[36] J. Jiang, H. Wang, W. Li, X. Cao, and C. Li, “Amyloid plaques in retina for diagnosis in Alzheimer's patients: a metaanalysis," Frontiers in Aging Neuroscience, vol. 8, p. 267, 2016.

[37] C. La Morgia, F. N. Ross-Cisneros, Y. Koronyo et al., "Melanopsin retinal ganglion cell loss in Alzheimer disease," Annals of Neurology, vol. 79, no. 1, pp. 90-109, 2016.

[38] Y. Koronyo, D. Biggs, E. Barron et al., "Retinal amyloid pathology and proof-of-concept imaging trial in Alzheimer's disease," JCI Insight, vol. 2, no. 16, 2017.

[39] P. N. Alexandrov, A. Pogue, S. Bhattacharjee, and W. J. Lukiw, "Retinal amyloid peptides and complement factor $\mathrm{H}$ in transgenic models of Alzheimer's disease," Neuroreport, vol. 22, no. 12, pp. 623-627, 2011. 
[40] Y. Tsai, B. Lu, A. V. Ljubimov et al., "Ocular changes in TgF344-AD rat model of Alzheimer's disease," Investigative Ophthalmology and Visual Science, vol. 55, no. 1, pp. 523534, 2014.

[41] M. Chiasseu, L. Alarcon-Martinez, N. Belforte et al., "Tau accumulation in the retina promotes early neuronal dysfunction and precedes brain pathology in a mouse model of Alzheimer's disease," Molecular Neurodegeneration, vol. 12, no. 1, p. 58, 2017.

[42] L. Buccarello, A. Sclip, M. Sacchi et al., "The c-jun N-terminal kinase plays a key role in ocular degenerative changes in a mouse model of Alzheimer disease suggesting a correlation between ocular and brain pathologies," Oncotarget, vol. 8, no. 47, pp. 83038-83051, 2017.

[43] C. Criscuolo, E. Cerri, C. Fabiani, S. Capsoni, A. Cattaneo, and L. Domenici, "The retina as a window to early dysfunctions of Alzheimer's disease following studies with a $5 \mathrm{xFAD}$ mouse model," Neurobiology of Aging, vol. 67, pp. 181-188, 2018.

[44] U. Kayabasi, R. C. Sergott, and M. Rispoli, "Retinal examination for the diagnosis of Alzheimer's disease," International Journal of Ophthalmic and Pathology, vol. 1, no. 1, pp. 3-4, 2014.

[45] N. J. Hart, Y. Koronyo, K. L. Black, and M. KoronyoHamaoui, "Ocular indicators of Alzheimer's: exploring disease in the retina," Acta Neuropathologica, vol. 132, no. 6, pp. 767-787, 2016.

[46] J. Doustar, T. Torbati, K. L. Black, Y. Koronyo, and M. Koronyo-Hamaoui, "Optical coherence tomography in Alzheimer's disease and other neurodegenerative diseases," Frontiers in Neurology, vol. 8, p. 701, 2017.

[47] H. Hampel, N. Toschi, C. Babiloni et al., "Revolution of Alzheimer precision neurology passageway of systems biology and neurophysiology," Journal of Alzheimer's Disease, vol. 64, no. S1, pp. S47-S105, 2018.

[48] K. Ukalovic, S. Cao, S. Lee et al., "Drusen in the peripheral retina of the Alzheimer's eye," Current Alzheimer Research, vol. 15, no. 8, pp. 743-750, 2018.

[49] V. K. Ramanan and A. J. Saykin, "Pathways to neurodegeneration: mechanistic insights from GWAS in Alzheimer's disease, Parkinson's disease, and related disorders," American Journal of Neurodegenerative Disease, vol. 2, no. 3 , pp. 145-175, 2013.

[50] S. L. Budd Haeberlein and T. J. Harris, "Promising targets for the treatment of neurodegenerative diseases," Clinical Pharmacology and Therapeutics, vol. 98, no. 5, pp. 492-501, 2015.

[51] J. Peedicayil, "Epigenetic targets for the treatment of neurodegenerative diseases," Clinical Pharmacology and Therapeutics, vol. 99, no. 5, p. 481, 2016.

[52] J. A. Santiago, V. Bottero, and J. A. Potashkin, "Dissecting the molecular mechanisms of neurodegenerative diseases through network biology," Frontiers in Aging Neuroscience, vol. 9, p. 166, 2017.

[53] C. Reitz and R. Mayeux, "Alzheimer disease: epidemiology, diagnostic criteria, risk factors and biomarkers," Biochemical Pharmacology, vol. 88, no. 4, pp. 640-651, 2014.

[54] P. van Wijngaarden, X. Hadoux, M. Alwan, S. Keel, and M. Dirani, "Emerging ocular biomarkers of Alzheimer disease," Clinical and Experimental Ophthalmology, vol. 45, no. 1, pp. 54-61, 2017.

[55] F. Chiti and C. M. Dobson, "Protein misfolding, amyloid formation, and human disease: a summary of progress over the last decade," Annual Review of Biochemistry, vol. 86, pp. 27-68, 2017.
[56] E. Herczenik and M. F. B. G. Gebbink, "Molecular and cellular aspects of protein misfolding and disease," FASEB Journal, vol. 22, no. 7, pp. 2115-2133, 2008.

[57] L. E. Goldstein, J. A. Muffat, R. A. Cherny et al., "Cytosolic beta-amyloid deposition and supranuclear cataracts in lenses from people with Alzheimer's disease," The Lancet, vol. 361, no. 9365 , pp. $1258-1265,2003$.

[58] M. B. Pepys, "Amyloidosis," Annual Review of Medicine, vol. 57, no. 1, pp. 223-241, 2006.

[59] V. K. Gupta, N. Chitranshi, V. B. Gupta et al., "Amyloid beta accumulation and inner retinal degenerative changes in Alzheimer's disease transgenic mouse," Neuroscience Letters, vol. 623 , pp. 52-56, 2016.

[60] E. Stefansson, O. B. Olafsdottir, A. B. Einarsdottir et al., "Retinal oximetry discovers novel biomarkers in retinal and brain diseases," Investigative Ophthalmology and Visual Science, vol. 58, no. 6, pp. 227-233, 2017.

[61] J. Attems and K. A. Jellinger, "Tau and alpha-synuclein brainstem pathology in Alzheimer disease," Neuropathology and Applied Neurobiology, vol. 32, no. 2, pp. 222-223, 2006.

[62] N. A. Verwey, A. Schuitemaker, W. M. van der Flier et al., "Serum amyloid P component as a biomarker in mild cognitive impairment and Alzheimer's disease," Dementia and Geriatric Cognitive Disorders, vol. 26, no. 6, pp. 522-527, 2008.

[63] V. L. Villemagne, K. E. Pike, D. Darby et al., "A beta deposits in older non-demented individuals with cognitive decline are indicative of preclinical Alzheimer's disease," Neuropsychologia, vol. 46, no. 6, pp. 1688-1697, 2008.

[64] N. K. Archibald, M. P. Clarke, U. P. Mosimann, and D. J. Burn, "The retina in Parkinson's disease," Brain, vol. 132, no. 5, pp. 1128-1145, 2009.

[65] I. Bodis-Wollner, P. B. Kozlowski, S. Glazman, and S. Miri, " $\alpha$-synuclein in the inner retina in Parkinson disease," Annals of Neurology, vol. 75, no. 6, pp. 964-966, 2014.

[66] L. V. Johnson, W. P. Leitner, A. J. Rivest, M. K. Staples, M. J. Radeke, and D. H. Anderson, "The Alzheimer's a betapeptide is deposited at sites of complement activation in pathologic deposits associated with aging and age-related macular degeneration," Proceedings of the National Academy of Sciences of the United States of America, vol. 99, no. 18, pp. 11830-11835, 2002.

[67] S. J. McKinnon, N. L. Ransom, N. G. Tahzih, D. M. Lehmann, and H. A. Reitsamer, "A monoclonal antibody to amyloid precursor protein induces apoptosis in rat retinal ganglion cells," Investigative Ophthalmology and Visual Science, vol. 43, article U1158-U, 2002.

[68] S. Yoneda, H. Hara, A. Hirata, M. Fukushima, Y. Inomata, and H. Tanihara, "Vitreous fluid levels of beta-amyloid((142)) and tau in patients with retinal diseases," Japanese Journal of Ophthalmology, vol. 49, no. 2, pp. 106-108, 2005.

[69] D. Goldblum, A. Kipfer-Kauer, G. M. Sarra, S. Wolf, and B. E. Frueh, "Distribution of amyloid precursor protein and amyloid-beta immunoreactivity in DBA/2J glaucomatous mouse retinas," Investigative Ophthalmology and Visual Science, vol. 48, no. 11, pp. 5085-5090, 2007.

[70] L. Guo, T. E. Salt, V. Luong et al., "Targeting amyloid-beta in glaucoma treatment," Proceedings of the National Academy of Sciences, vol. 104, no. 33, pp. 13444-13449, 2007.

[71] R. Mancino, A. Martucci, M. Cesareo et al., "Glaucoma and Alzheimer disease: a single age-related neurodegenerative disease of the brain," Current Neuropharmacology, vol. 16, no. 7, pp. 971-977, 2017. 
[72] M. Mirzaei, V. B. Gupta, J. M. Chick et al., "Age-related neurodegenerative disease associated pathways identified in retinal and vitreous proteome from human glaucoma eyes," Scientific Reports, vol. 7, no. 1, article 12685, 2017.

[73] E. Cerri, C. Fabiani, C. Criscuolo, and L. Domenici, "Visual Evoked Potentials in Glaucoma and Alzheimer's Disease," Methods in Molecular Biology, vol. 1695, pp. 69-80, 2018.

[74] A. Giorgio, J. Zhang, F. Costantino, N. De Stefano, and P. Frezzotti, "Diffuse brain damage in normal tension glaucoma," Human Brain Mapping, vol. 39, no. 1, pp. 532541, 2018.

[75] P. Wostyn, D. Van Dam, K. Audenaert, H. E. Killer, P. P. De Deyn, and V. De Groot, "A new glaucoma hypothesis: a role of glymphatic system dysfunction," Fluids and Barriers of the CNS, vol. 12, p. 16, 2015.

[76] N. A. Jessen, A. S. Munk, I. Lundgaard, and M. Nedergaard, "The glymphatic system: a beginner's guide," Neurochemical Research, vol. 40, no. 12, pp. 2583-2599, 2015.

[77] P. Wostyn, V. De Groot, D. Van Dam, K. Audenaert, H. E. Killer, and P. P. De Deyn, "The Glymphatic Hypothesis of Glaucoma: A Unifying Concept Incorporating Vascular, Biomechanical, and Biochemical Aspects of the Disease," BioMed Research International, vol. 2017, Article ID 5123148, 7 pages, 2017.

[78] P. Wostyn, H. E. Killer, and P. P. De Deyn, "Glymphatic stasis at the site of the lamina cribrosa as a potential mechanism underlying open-angle glaucoma," Clinical and Experimental Ophthalmology, vol. 45, no. 5, pp. 539-547, 2017.

[79] L. Biscetti, E. Luchetti, A. Vergaro, P. Menduno, C. Cagini, and L. Parnetti, "Associations of Alzheimer's disease with macular degeneration," Frontiers in Bioscience, vol. 9, no. 1, pp. 174-191, 2017.

[80] A. I. Pogue and W. J. Lukiw, "Up-regulated proinflammatory microRNAs (miRNAs) in Alzheimer's disease (AD) and age-related macular degeneration (AMD)," Cellular and Molecular Neurobiology, vol. 38, no. 5, pp. 1021-1031, 2018.

[81] S. Frost, R. Guymer, K. Z. Aung et al., "Alzheimer's disease and the early signs of age-related macular degeneration," Current Alzheimer Research, vol. 13, no. 11, pp. 1259-1266, 2016.

[82] D. Seden, G. Alime, D. Kadir, D. Serpil, T. Levent, and T. Ozlem, "Is Alzheimer disease related to age-related macular degeneration?," Turkish Journal of Medical Sciences, vol. 45, no. 5, pp. 1115-1121, 2015.

[83] M. A. Williams, G. J. McKay, R. Carson, D. Craig, G. Silvestri, and P. Passmore, "Age-related macular degeneration-associated genes in Alzheimer disease," American Journal of Geriatric Psychiatry, vol. 23, no. 12, pp. 1290-1296, 2015.

[84] R. Sant'Anna, S. Navarro, S. Ventura, L. Paraoan, and D. Foguel, "Amyloid properties of the leader peptide of variant B cystatin C: implications for Alzheimer and macular degeneration," FEBS Letters, vol. 590, no. 5, pp. 644-654, 2016.

[85] D. R. Hinton, A. A. Sadun, J. C. Blanks, and C. A. Miller, "Optic-nerve degeneration in Alzheimer's disease," New England Journal of Medicine, vol. 315, no. 8, pp. 485-487, 1986.

[86] J. C. Blanks, D. R. Hinton, A. A. Sadun, and C. A. Miller, "Retinal ganglion cell degeneration in Alzheimer's disease," Brain Research, vol. 501, no. 2, pp. 364-372, 1989.

[87] A. A. Sadun and C. J. Bassi, "Optic-nerve damage in Alzheimer's disease," Ophthalmology, vol. 97, no. 1, pp. 9-17, 1990.

[88] J. C. Blanks, S. Y. Schmidt, Y. Torigoe, K. V. Porrello, D. R. Hinton, and R. H. I. Blanks, "Retinal pathology in Alzheimer's disease. 2. Regional neuron loss and glial changes in GCL," Neurobiology of Aging, vol. 17, no. 3, pp. 385-395, 1996.

[89] T. R. Hedges, R. Perez Galves, D. Speigelman, N. R. Barbas, E. Peli, and C. J. Yardley, "Retinal nerve fiber layer abnormalities in Alzheimer's disease," Acta Ophthalmologica Scandinavica, vol. 74, no. 3, pp. 271-275, 1996.

[90] J. C. Blanks, Y. Torigoe, D. R. Hinton, and R. H. I. Blanks, "Retinal pathology in Alzheimer's disease. 1. Ganglion cell loss in foveal/parafoveal retina," Neurobiology of Aging, vol. 17, no. 3, pp. 377-384, 1996.

[91] P. K. Iseri, O. Altinas, T. Tokay, and N. Yuksel, "Relationship between cognitive impairment and retinal morphological and visual functional abnormalities in Alzheimer disease," Journal of Neuro-Ophthalmology, vol. 26, no. 1, pp. 18-24, 2006.

[92] A. U. Bayer, O. N. Keller, F. Ferrari, and K. P. Maag, “Association of glaucoma with neurodegenerative diseases with apoptotic cell death: Alzheimer's disease and Parkinson's disease," American Journal of Ophthalmology, vol. 133, no. 1, pp. 135-137, 2002.

[93] V. Parisi, R. Restuccia, F. Fattapposta, C. Mina, M. G. Bucci, and F. Pierelli, "Morphological and functional retinal impairment in Alzheimer's disease patients," Clinical Neurophysiology, vol. 112, no. 10, pp. 1860-1867, 2001.

[94] R. Patil, Y. Koronyo, A. V. Ljubimov et al., "Advances in Imaging: brain tumors to Alzheimer's disease," Bangkok Medical Journal, vol. 10, no. 1, pp. 83-97, 2015.

[95] J. K. Morris, R. A. Honea, E. D. Vidoni, R. H. Swerdlow, and J. M. Burns, "Is Alzheimer's disease a systemic disease?," Biochimica et Biophysica Acta, vol. 1842, no. 9, pp. 13401349, 2014.

[96] M. Oresic, G. Anderson, I. Mattila et al., "Targeted serum metabolite profiling identifies metabolic signatures in patients with Alzheimer's disease, normal pressure hydrocephalus and brain tumor," Frontiers in Neuroscience, vol. 11, p. 747, 2017.

[97] A. B. Einarsdottir, S. H. Hardarson, J. V. Kristjansdottir, D. T. Bragason, J. Snaedal, and E. Stefansson, "Retinal oximetry imaging in Alzheimer's disease," Journal of Alzheimer's Disease, vol. 49, no. 1, pp. 79-83, 2016.

[98] G. Alcarraz-Vizan, P. Casini, L. Cadavez et al., "Inhibition of BACE2 counteracts hIAPP-induced insulin secretory defects in pancreatic beta-cells," FASEB Journal, vol. 29, no. 1, pp. 95-104, 2015.

[99] R. Simo, A. Ciudin, O. Simo-Servat, and C. Hernandez, "Cognitive impairment and dementia: a new emerging complication of type 2 diabetes-the diabetologist's perspective," Acta Diabetologica, vol. 54, no. 5, pp. 417-424, 2017.

[100] A. Ciudin, O. Simo-Servat, C. Hernandez et al., "Retinal microperimetry: a new tool for identifying patients with type 2 diabetes at risk for developing Alzheimer disease," $D i$ abetes, vol. 66, no. 12, pp. 3098-3104, 2017.

[101] M. B. Rougier, J. F. Korobelnik, F. Malet et al., "Retinal nerve fibre layer thickness measured with SD-OCT in a populationbased study of French elderly subjects: the Alienor study," Acta Ophthalmologica, vol. 93, no. 6, pp. 539-545, 2015.

[102] C. Schweitzer, J. F. Korobelnik, M. Le Goff et al., "Diagnostic performance of peripapillary retinal nerve fiber layer thickness for detection of glaucoma in an elderly population: the Alienor study," Investigative Ophthalmology and Visual Science, vol. 57, no. 14, pp. 5882-5891, 2016.

[103] L. Tellouck, M. Durieux, P. Coupe et al., "Optic radiations microstructural changes in glaucoma and association with 
severity: a study using 3 tesla-magnetic resonance diffusion tensor imaging," Investigative Ophthalmology and Visual Science, vol. 57, no. 15, pp. 6539-6547, 2016.

[104] J. L. Mendez-Gomez, M. B. Rougier, L. Tellouck et al., "Peripapillary retinal nerve fiber layer thickness and the evolution of cognitive performance in an elderly population," Frontiers in Neurology, vol. 8, p. 93, 2017.

[105] K. G. Goozee, T. M. Shah, H. R. Sohrabi et al., "Examining the potential clinical value of curcumin in the prevention and diagnosis of Alzheimer's disease," British Journal of Nutrition, vol. 115, no. 3, pp. 449-465, 2016.

[106] M. Chen, Z. Y. Du, X. Zheng, D. L. Li, R. P. Zhou, and K. Zhang, "Use of curcumin in diagnosis, prevention, and treatment of Alzheimer's disease," Neural Regeneration Research, vol. 13, no. 4, pp. 742-752, 2018.

[107] A. Ning, J. Cui, E. To, K. H. Ashe, and J. Matsubara, “Amyloidbeta deposits lead to retinal degeneration in a mouse model of Alzheimer disease," Investigative Ophthalmology and Visual Science, vol. 49, no. 11, pp. 5136-5143, 2008.

[108] S. E. Perez, S. Lumayag, B. Kovacs, E. J. Mufson, and S. B. Xu, " $\beta$-amyloid deposition and functional impairment in the retina of the APPswe/PS1 delta E9 transgenic mouse model of Alzheimer's disease," Investigative Ophthalmology and Visual Science, vol. 50, no. 2, pp. 793-800, 2009.

[109] K. Chiu, T. F. Chan, A. Wu, I. Y. P. Leung, K. F. So, and R. C. C. Chang, "Neurodegeneration of the retina in mouse models of Alzheimer's disease: what can we learn from the retina?," Age, vol. 34, no. 3, pp. 633-649, 2012.

[110] J. C. Vickers, R. A. Lazzarini, B. M. Riederer, and J. H. Morrison, "Intraperikaryal neurofilamentous accumulations in a subset of retinal ganglion-cells in aged mice that express a human neurofilament gene," Experimental Neurology, vol. 136, no. 2, pp. 266-269, 1995.

[111] A. I. Ramirez, R. de Hoz, E. Salobrar-Garcia et al., "The role of microglia in retinal neurodegeneration: Alzheimer's disease, Parkinson, and glaucoma," Frontiers in Aging Neuroscience, vol. 9, p. 214, 2017.

[112] D. J. Mordant, I. Al-Abboud, G. Muyo, A. Gorman, A. R. Harvey, and A. I. McNaught, "Oxygen saturation measurements of the retinal vasculature in treated asymmetrical primary open-angle glaucoma using hyperspectral imaging," Eye, vol. 28, no. 10, pp. 1190-1200, 2014.

[113] A. M. Shahidi, S. R. Patel, J. G. Flanagan, and C. Hudson, "Regional variation in human retinal vessel oxygen saturation," Experimental Eye Research, vol. 113, pp. 143-147, 2013.

[114] K. Rose, S. I. Kulasekara, and C. Hudson, "Intervisit repeatability of retinal blood oximetry and total retinal blood flow under varying systemic blood gas oxygen saturations," Investigative Ophthalmology and Visual Science, vol. 57, no. 1, pp. 188-197, 2016.

[115] K. Herrup, "The case for rejecting the amyloid cascade hypothesis," Nature Neuroscience, vol. 18, no. 6, pp. 794-799, 2015.

[116] S. S. More and R. Vince, "Hyperspectral imaging signatures detect amyloidopathy in Alzheimer's mouse retina well before onset of cognitive decline," ACS Chemical Neuroscience, vol. 6, no. 2, pp. 306-315, 2015.

[117] S. S. More, J. M. Beach, and R. Vince, "Early detection of amyloidopathy in Alzheimer's mice by hyperspectral endoscopy," Investigative Ophthalmology and Visual Science, vol. 57, no. 7, pp. 3231-3238, 2016.

[118] C. Schon, N. A. Hoffmann, S. M. Ochs et al., "Long-term in vivo imaging of fibrillar tau in the retina of P301S transgenic mice," PLoS One, vol. 7, no. 12, Article ID e53547, 2012.
[119] P. A. Williams, R. A. Thirgood, H. Oliphant et al., "Retinal ganglion cell dendritic degeneration in a mouse model of Alzheimer's disease," Neurobiology of Aging, vol. 34, no. 7, pp. 1799-1806, 2013.

[120] H. Zhao, R. Chang, H. Che et al., "Hyperphosphorylation of tau protein by calpain regulation in retina of Alzheimer's disease transgenic mouse," Neuroscience Letters, vol. 551, pp. 12-16, 2013.

[121] C. Y. Ho, J. C. Troncoso, D. Knox, W. Stark, and C. G. Eberhart, "Beta-amyloid, phospho-tau and alphasynuclein deposits similar to those in the brain are not identified in the eyes of Alzheimer's and Parkinson's disease patients," Brain Pathology, vol. 24, no. 1, pp. 25-32, 2014.

[122] D. E. Barnes and K. Yaffe, "The projected effect of risk factor reduction on Alzheimer's disease prevalence," Lancet Neurology, vol. 10, no. 9, pp. 819-828, 2011.

[123] C. Reitz, C. Brayne, and R. Mayeux, "Epidemiology of Alzheimer disease," Nature Reviews Neurology, vol. 7, no. 3, pp. 137-152, 2011

[124] C. Kerbage, C. H. Sadowsky, D. Jennings, G. D. Cagle, and P. D. Hartung, "Alzheimer's disease diagnosis by detecting exogenous fluorescent signal of ligand bound to beta amyloid in the lens of human eye: an exploratory study," Frontiers in Neurology, vol. 4, 2013.

[125] K. L. Thomson, J. M. Yeo, B. Waddell, J. R. Cameron, and S. Pal, "A systematic review and meta-analysis of retinal nerve fiber layer change in dementia, using optical coherence tomography," Alzheimer's and Dementia, vol. 1, no. 2, pp. 136-143, 2015.

[126] L. P. Cunha, L. C. Lopes, L. V. F. Costa-Cunha et al., "Macular thickness measurements with frequency domain-OCT for quantification of retinal neural loss and its correlation with cognitive impairment in Alzheimer's disease," PLoS One, vol. 11, no. 4, Article ID e0153830, 2016.

[127] J. den Haan, S. F. Janssen, J. A. van de Kreeke, P. Scheltens, F. D. Verbraak, and F. H. Bouwman, "Retinal thickness correlates with parietal cortical atrophy in early-onset Alzheimer's disease and controls," Alzheimer's and Dementia, vol. 10, pp. 49-55, 2018.

[128] S. Frost, Y. Kanagasingam, H. Sohrabi et al., "Retinal vascular biomarkers for early detection and monitoring of Alzheimer's disease," Translational psychiatry, vol. 3, article e233, 2013.

[129] H. Jiang, Y. Wei, Y. Shi et al., "Altered macular microvasculature in mild cognitive impairment and Alzheimer disease," Journal of Neuro-Ophthalmology, 2017, In press.

[130] K. Kotliar, C. Hauser, M. Ortner et al., "Altered neurovascular coupling as measured by optical imaging: a biomarker for Alzheimer's disease," Scientific Reports, vol. 7, no. 1, article 12906, 2017.

[131] M. Bulut, F. Kurtulus, O. Gozkaya et al., "Evaluation of optical coherence tomography angiographic findings in Alzheimer's type dementia," British Journal of Ophthalmology, vol. 102, no. 2, pp. 233-237, 2018.

[132] G. Seidel, G. Aschinger, C. Singer et al., "Estimating retinal blood flow velocities by optical coherence tomography," JAMA Ophthalmology, vol. 134, no. 10, pp. 1104-1110, 2016.

[133] G. C. Aschinger, L. Schmetterer, K. Fondi et al., "Effect of diffuse luminance flicker light stimulation on total retinal blood flow assessed with dual-beam bidirectional Doppler OCT," Investigative Ophthalmology and Visual Science, vol. 58, no. 2, pp. 1167-1178, 2017. 
[134] B. Baumann, A. Woehrer, G. Ricken et al., "Visualization of neuritic plaques in Alzheimer's disease by polarizationsensitive optical coherence microscopy," Scientific Reports, vol. 7, article 43477, 2017.

[135] M. Ang, M. Baskaran, R. M. Werkmeister et al., "Anterior segment optical coherence tomography," Progress in Retinal and Eye Research, 2018, In press.

[136] G. Kallo, M. Emri, Z. Varga et al., "Changes in the chemical barrier composition of tears in Alzheimer's disease reveal potential tear diagnostic biomarkers," PLoS One, vol. 11, no. 6, Article ID e0158000, 2016.

[137] N. Ornek, E. Dag, and K. Ornek, "Corneal sensitivity and tear function in neurodegenerative diseases," Current Eye Research, vol. 40, no. 4, pp. 423-428, 2015.

[138] T. L. Spires-Jones, W. H. Stoothoff, A. de Calignon, P. B. Jones, and B. T. Hyman, "Tau pathophysiology in neurodegeneration: a tangled issue," Trends in Neurosciences, vol. 32, no. 3, pp. 150-159, 2009.

[139] A. Mudher and S. Lovestone, "Alzheimer's disease-do tauists and baptists finally shake hands?," Trends in Neurosciences, vol. 25, no. 1, pp. 22-26, 2002.

[140] P. Rusu, A. Jansen, P. Soba et al., "Axonal accumulation of synaptic markers in APP transgenic Drosophila depends on the NPTY motif and is paralleled by defects in synaptic plasticity," European Journal of Neuroscience, vol. 25, no. 4, pp. 1079-1086, 2007.

[141] R. M. Dutescu, Q. X. Li, J. Crowston, C. L. Masters, P. N. Baird, and J. G. Culvenor, "Amyloid precursor protein processing and retinal pathology in mouse models of Alzheimer's disease," Graefe's Archive for Clinical and Experimental Ophthalmology, vol. 247, no. 9, pp. 1213-1221, 2009.

[142] L. Gao, X. Chen, Y. Tang et al., "Neuroprotective effect of memantine on the retinal ganglion cells of APPswe/ PS1DeltaE9 mice and its immunomodulatory mechanisms," Experimental Eye Research, vol. 135, pp. 47-58, 2015.

[143] F. Berisha, G. T. Feke, C. L. Trempe, J. W. McMeel, and C. L. Schepens, "Retinal abnormalities in early Alzheimer's disease," Investigative Ophthalmology and Visual Science, vol. 48, no. 5, pp. 2285-2289, 2007.

[144] A. Trebbastoni, F. D’Antonio, A. Bruscolini et al., "Retinal nerve fibre layer thickness changes in Alzheimer's disease: results from a 12-month prospective case series," Neuroscience Letters, vol. 629, pp. 165-170, 2016.

[145] G. Coppola, A. Di Renzo, L. Ziccardi et al., "Optical coherence tomography in Alzheimer's disease: a meta-analysis," PLoS One, vol. 10, no. 8, Article ID e0134750, 2015.

[146] C. B. Saper, D. C. German, and C. L. White, "Neuronal pathology in the nucleus basalis and associated cell groups in senile dementia of the Alzheimer's type: possible role in cell loss," Neurology, vol. 35, no. 8, pp. 1089-1095, 1985.

[147] W. J. Burke, H. D. Chung, J. S. Huang et al., "Evidence for retrograde degeneration of epinephrine neurons in Alzheimer's disease," Annals of Neurology, vol. 24, no. 4, pp. 532-536, 1988.

[148] M. T. Heneka, M. J. Carson, J. El Khoury et al., "Neuroinflammation in Alzheimer's disease," Lancet Neurology, vol. 14 , no. 4 , pp. 388-405, 2015.

[149] A. Swanson, T. Wolf, A. Sitzmann, and A. A. Willette, "Neuroinflammation in Alzheimer's disease: pleiotropic roles for cytokines and neuronal pentraxins," Behavioural Brain Research, vol. 347, pp. 49-56, 2018.

[150] H. Fillit, W. H. Ding, L. Buee et al., "Elevated circulating tumor necrosis factor levels in Alzheimer's disease," Neuroscience Letters, vol. 129, no. 2, pp. 318-320, 1991.
[151] D. Paris, N. Patel, A. DelleDonne, A. Quadros, R. Smeed, and M. Mullan, "Impaired angiogenesis in a transgenic mouse model of cerebral amyloidosis," Neuroscience Letters, vol. 366, no. 1, pp. 80-85, 2004.

[152] G. T. Feke, B. T. Hyman, R. A. Stern, and L. R. Pasquale, "Retinal blood flow in mild cognitive impairment and Alzheimer's disease," Alzheimer's and Dementia, vol. 1, no. 2, pp. 144-151, 2015.

[153] C. S. Tsai, R. Ritch, B. Schwartz et al., "Optic nerve head and nerve fiber layer in Alzheimer's disease," Archives of Ophthalmology, vol. 109, no. 2, pp. 199-204, 1991.

[154] A. Kesler, V. Vakhapova, A. D. Korczyn, E. Naftaliev, and M. Neudorfer, "Retinal thickness in patients with mild cognitive impairment and Alzheimer's disease," Clinical Neurology and Neurosurgery, vol. 113, no. 7, pp. 523-526, 2011.

[155] M. P. Bambo, E. Garcia-Martin, F. Gutierrez-Ruiz et al., "Analysis of optic disk color changes in Alzheimer's disease: a potential new biomarker," Clinical Neurology and Neurosurgery, vol. 132, pp. 68-73, 2015.

[156] S. S. Liu and S. Q. Zhu, "Correlation between Alzheimer disease and cataract," Chinese Journal of Ophthalmology, vol. 53, no. 4, pp. 314-316, 2017.

[157] T. Tian, B. Zhang, Y. Jia, and Z. Li, "Promise and challenge: the lens model as a biomarker for early diagnosis of Alzheimer's disease," Disease Markers, vol. 2014, Article ID 826503, 5 pages, 2014.

[158] E. L. Granholm, M. S. Panizzon, J. A. Elman et al., "Pupillary responses as a biomarker of early risk for Alzheimer's disease," Journal of Alzheimer's Disease, vol. 56, no. 4, pp. 1419-1428, 2017.

[159] R. A. Sperling, P. S. Aisen, L. A. Beckett et al., "Toward defining the preclinical stages of Alzheimer's disease: recommendations from the National Institute on Aging-Alzheimer's Association workgroups on diagnostic guidelines for Alzheimer's disease," Alzheimer's and dementia, vol. 7, no. 3, pp. 280-292, 2011.

[160] A. Trebbastoni, M. Marcelli, F. Mallone et al., "Attenuation of choroidal thickness in patients with Alzheimer Disease: evidence from an Italian prospective study," Alzheimer Disease and Associated Disorders, vol. 31, no. 2, pp. 128-134, 2017.

[161] P. Jirarattanasopa, S. Ooto, I. Nakata et al., "Choroidal thickness, vascular hyperpermeability, and complement factor $\mathrm{H}$ in age-related macular degeneration and polypoidal choroidal vasculopathy," Investigative Ophthalmology and Visual Science, vol. 53, no. 7, pp. 3663-3672, 2012.

[162] T. Inoue, T. Kawaji, and H. Tanihara, "Elevated levels of multiple biomarkers of Alzheimer's disease in the aqueous humor of eyes with open-angle glaucoma," Investigative Ophthalmology and Visual Science, vol. 54, no. 8, pp. 5353-5358, 2013.

[163] S. Janciauskiene, K. Westin, O. Grip, and T. Krakau, "Detection of Alzheimer peptides and chemokines in the aqueous humor," European Journal of Ophthalmology, vol. 21, no. 1, pp. 104-111, 2011.

[164] G. C. Gilmore and J. A. Levy, "Spatial contrast sensitivity in Alzheimer's disease: a comparison of two methods," Optometry and Vision Science, vol. 68, no. 10, pp. 790-794, 1991.

[165] V. Polo, M. J. Rodrigo, E. Garcia-Martin et al., "Visual dysfunction and its correlation with retinal changes in patients with Alzheimer's disease," Eye, vol. 31, no. 7, pp. 1034-1041, 2017. 
[166] S. N. Thiyagesh, T. F. Farrow, R. W. Parks et al., "The neural basis of visuospatial perception in Alzheimer's disease and healthy elderly comparison subjects: an fMRI study," Psychiatry Research, vol. 172, no. 2, pp. 109-116, 2009.

[167] F. K. Cormack, M. Tovee, and C. Ballard, "Contrast sensitivity and visual acuity in patients with Alzheimer's disease," International Journal of Geriatric Psychiatry, vol. 15, no. 7, pp. 614-620, 2000.

[168] M. Mapstone, K. Dickerson, and C. J. Duffy, "Distinct mechanisms of impairment in cognitive ageing and Alzheimer's disease," Brain, vol. 131, no. 6, pp. 1618-1629, 2008.

[169] G. C. Gilmore, H. E. Wenk, L. A. Naylor, and E. Koss, "Motion perception and Alzheimer's disease," Journal of Gerontology, vol. 49, no. 2, pp. P52-P57, 1994.

[170] M. Rizzo and M. Nawrot, "Perception of movement and shape in Alzheimer's disease," Brain, vol. 121, no. 12, pp. 2259-2270, 1998.

[171] A. Cronin-Golomb, R. Sugiura, S. Corkin, and J. H. Growdon, "Incomplete achromatopsia in Alzheimer's disease," Neurobiology of Aging, vol. 14, no. 5, pp. 471-477, 1993.

[172] H. Bridge, "Effects of cortical damage on binocular depth perception," Philosophical Transactions of the Royal Society B: Biological Sciences, vol. 371, no. 1697, article 20150254, 2016.

[173] W. Mittenberg, E. J. Choi, and C. C. Apple, "Stereoscopic visual impairment in vascular dementia," Archives of Clinical Neuropsychology, vol. 15, no. 7, pp. 561-569, 2000.

[174] R. Feng, L. Li, H. Yu, M. I. N. Liu, and W. E. I. Zhao, "Melanopsin retinal ganglion cell loss and circadian dysfunction in Alzheimer's disease (review)," Molecular Medicine Reports, vol. 13, no. 4, pp. 3397-3400, 2016.

[175] C. La Morgia, F. N. Ross-Cisneros, A. A. Sadun, and V. Carelli, "Retinal ganglion cells and circadian rhythms in Alzheimer's disease, Parkinson's disease, and beyond," Frontiers in Neurology, vol. 8, p. 162, 2017.

[176] E. S. Musiek, D. D. Xiong, and D. M. Holtzman, "Sleep, circadian rhythms, and the pathogenesis of Alzheimer Disease," Experimental and Molecular Medicine, vol. 47, no. 3, article e148, 2015.

[177] A. Tales, T. Troscianko, D. Lush, J. Haworth, G. K. Wilcock, and S. R. Butler, "The pupillary light reflex in aging and Alzheimer's disease," Aging, vol. 13, no. 6, pp. 473-478, 2001.

[178] "Familial aggregation and prevalence of myopia in the Framingham offspring eye study," Archives of Ophthalmology, vol. 114, no. 3, pp. 326-332, 1996.

[179] J. A. Moncaster, R. Pineda, R. D. Moir et al., "Alzheimer's disease amyloid-beta links lens and brain pathology in Down syndrome," PLoS One, vol. 5, no. 5, Article ID e10659, 2010.

[180] I. Sotiropoulos, C. Catania, T. Riedemann et al., "Glucocorticoids trigger Alzheimer disease-like pathobiochemistry in rat neuronal cells expressing human tau," Journal of Neurochemistry, vol. 107, no. 2, pp. 385-397, 2008.

[181] A. I. Pogue, P. Dua, J. M. Hill, and W. J. Lukiw, "Progressive inflammatory pathology in the retina of aluminum-fed $5 x F A D$ transgenic mice," Journal of Inorganic Biochemistry, vol. 152, pp. 206-209, 2015. 


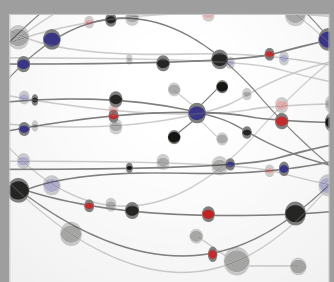

The Scientific World Journal
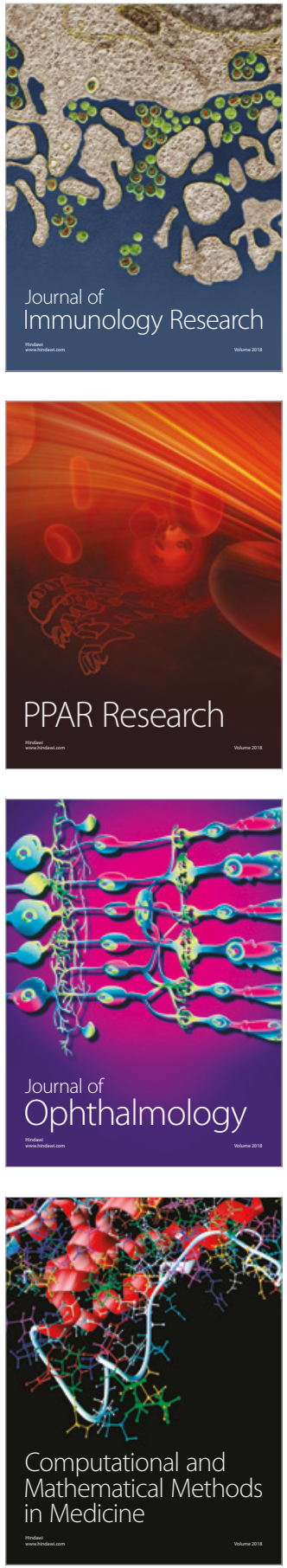

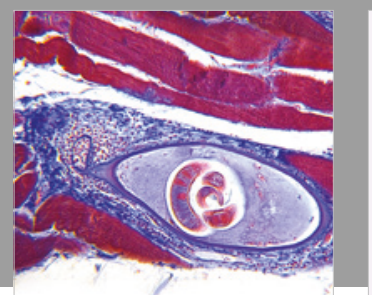

Gastroenterology Research and Practice

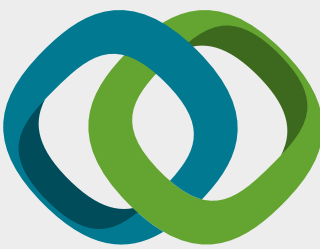

\section{Hindawi}

Submit your manuscripts at

www.hindawi.com
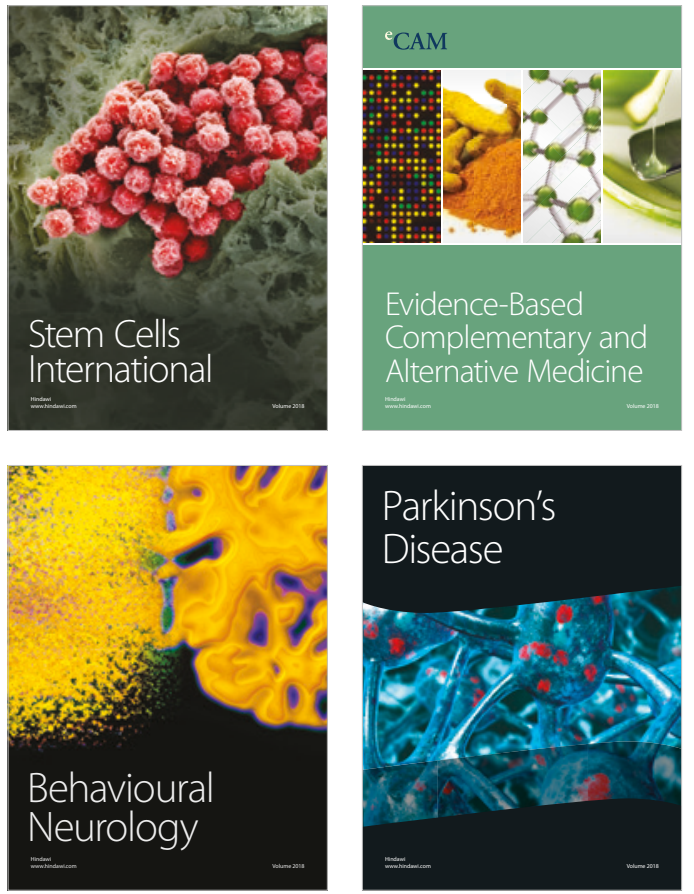

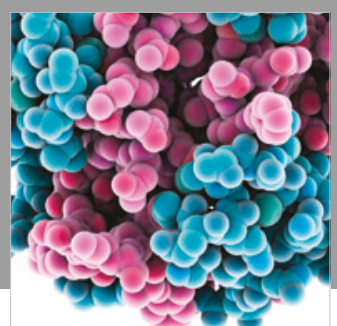

ournal of

Diabetes Research

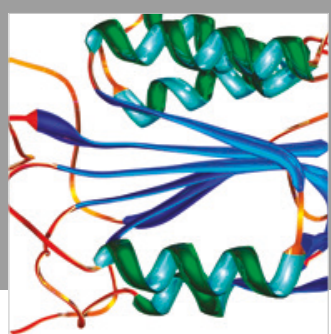

Disease Markers
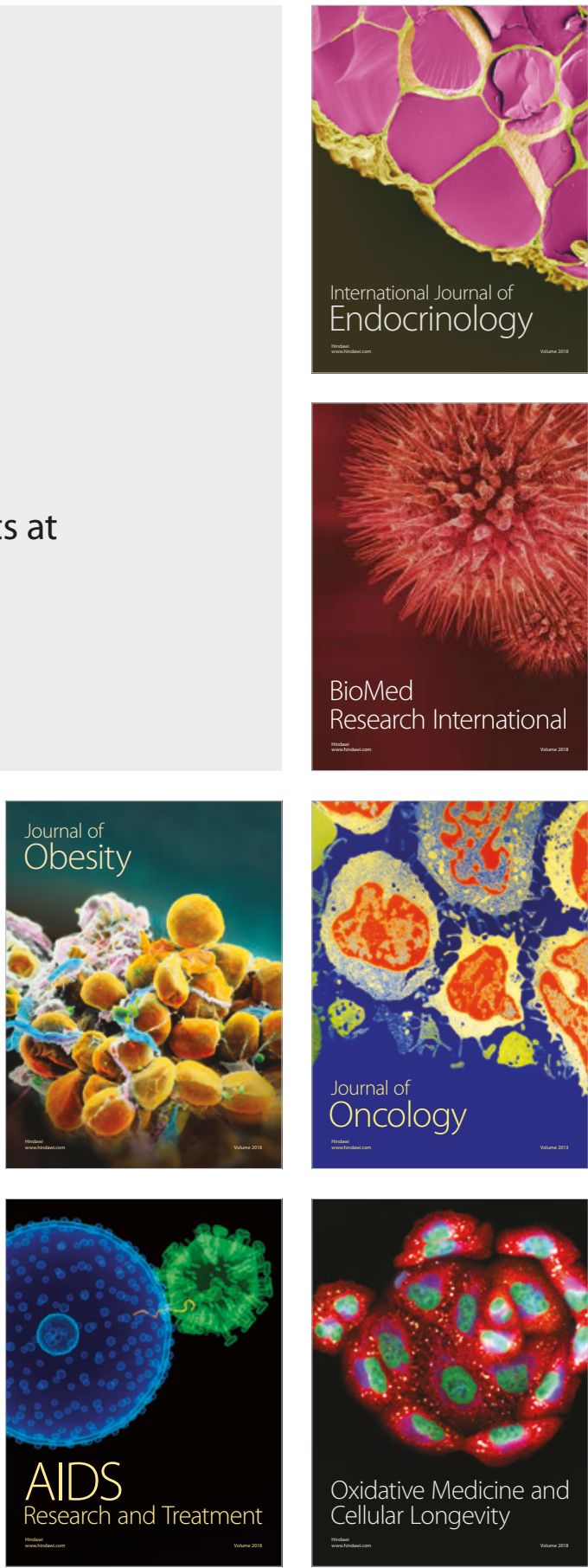